\title{
Simulação de Alagamentos sob a Perspectiva do Solo: Uma Extensão da Ferramenta SIGMAOn
}

\author{
David K.R. de Melo ${ }^{1}$, Diogo P. Scoz ${ }^{1}$, Fernando dos Santos ${ }^{2}$, Márcio J. Mantau ${ }^{2}$ \\ ${ }^{1}$ Departamento de Engenharia de Software - DESO \\ Centro de Educação Superior do Alto Vale do Itajaí - CEAVI \\ Universidade do Estado de Santa Catarina - UDESC \\ ${ }^{2}$ Pós Graduação em Engenharia de Software - PGES \\ Centro de Educação Superior do Alto Vale do Itajaí - CEAVI \\ Universidade do Estado de Santa Catarina - UDESC \\ \{diogoscoz, david.melo1992\}@gmail.com, \{fernando.santos, \\ marcio.mantau\}@udesc.br
}

\begin{abstract}
SIGMAOn is a Geographic Information System that offers a simulation feature allowing seeing flood points and areas, as well as routes in flooding scenarios. This paper presents a extension of the SIGMAOn in order to provide a flood impact visualization through pictures in a firs-person perspective. The work also aims to survey photos of flooding places, definition of techniques for extracting the meter measurement and drawing floods on pictures. Concepts of Geometry were used for projecting the flooded streets on pictures of floodable places. The work provides a way of viewing the floods from the ground perspective. In addition, the techniques for extracting the meter measurement and drawing floods on pictures were defined.
\end{abstract}

Resumo. SIGMAOn é um sistema de Informação Geográfica que oferece recursos de simulação de alagamentos com visualização de pontos e áreas alagadas, bem como rotas em cenários de inundação. Este artigo apresenta uma extensão do SIGMAOn para oferecer visualização de impacto de um alagamento por meio de fotos, sob uma perspectiva de visão em primeira pessoa. O trabalho também tem como objetivos o levantamento de fotos de locais alagáveis, definição de técnicas para extração de metragem e desenho de alagamentos sobre fotos. Foram aplicados conceitos de geometria para projeção de ruas alagadas sobre fotos de locais alagáveis. O trabalho oferece uma forma de visualização sob a perspectiva do solo. Além disso, foram definidas as técnicas de extração de metragem e projeção de alagamentos.

\section{Introdução}

Os desastres naturais vêm representando um prejuízo inegável no mundo todo. Dentre as causas, encontra-se ocupação irregular, acúmulo de lixo em bueiros e encostas de rios, além de condições geográficas favoráveis a esse tipo de catástrofe, como altitude das cidades, largura e profundidade dos rios. No caso das enchentes, o Brasil é um dos mais afetados, já que de acordo com Chade (2012) o país ocupa a $13^{a}$ posição em um ranking elaborado pela ONU que mede os países mais vulneráveis às enchentes. 
A região do Alto Vale do Itajaí, localizada no estado de Santa Catarina vem sofrendo ao longo da história sucessivos alagamentos. O município de Presidente Getúlio, quando ainda era uma colônia, no ano de 1911, passou por uma das maiores enchentes da história do Vale do Itajaí, que atingiu diversas cidades, chegando a 16,6 metros o nível das águas em Blumenau (WIESE, 2011). Ao longo do século XX, a região passou por outras diversas inundações, com destaque para a que ocorreu em 1983, e atingiu várias cidades do Vale do Itajaí. Segundo Rio do Sul (2012), naquela ocasião, o nível dos rios Itajaí do Sul, Itajaí do Oeste e Itajaí-Açu atingiu a marca de 15,08 metros.

O Alto Vale do Itajaí voltou a ter prejuízos com alagamentos no ano de 2011. O município de Presidente Getúlio teve prejuízo que ultrapassou 4 milhões de reais (PRESIDENTE GETÚLIO, 2011). Além disso, entre 1992 e 2012, os prejuízos com as enchentes custaram nove vezes mais que o investimento feito pelas autoridades para evitar mortes, o que mostra que os investimentos preventivos não tem sido o suficiente ou não foram feitos da melhor forma (CHADE, 2012).

Tais investimentos podem ser feitos de diversas formas, e vão depender do contexto. Segundo Wiese (2011), o problema está presente nos municípios do Alto Vale do Itajaí desde a chegada das primeiras colonizações, que se instalaram nas proximidades dos rios, dando início às cidades. Isso mostra que além de fiscalização para evitar a construção de novas casas em locais impróprios, faz-se necessário algum mecanismo de monitoramento que possibilite prever os desastres e minimizar as perdas.

Tendo em vista esse cenário, SIGMAOn (Sistema de Informação Geográfica para Monitoramento de Alagamentos On-line), desenvolvido por Floriano et al. (2014) é uma alternativa de caráter preventivo e diagnóstico, uma vez que possibilita a simulação de catástrofes tanto por parte de cidadãos quanto de autoridades para que possam mensurar de forma concreta e visual o impacto das catástrofes antes delas acontecerem.

Este trabalho propõe uma extensão para o SIGMAOn, para que possa oferecer uma forma de visualização de alagamentos sobre fotos dos locais alagáveis, sob um ponto de vista semelhante ao de uma pessoa no solo. A partir desta funcionalidade ficará ainda mais claro o impacto das cheias nas cidades.

A partir de conceitos de geometria analítica e com o auxílio de tecnologias de manipulação de imagens é possível desenhar o impacto de um alagamento sobre uma foto do local alagável, possibilitando uma forma de visualização mais concreta das consequências das cheias.

O trabalho se justifica por conta da contribuição que dará para a sociedade de forma geral, possibilitando não só uma forma dos cidadãos se prevenirem quanto a possíveis catástrofes, mas também se mostraria uma boa forma de diagnóstico por parte das autoridades competentes, que poderiam, a partir de informações claras e concretas, tomar as devidas providências para amenizar o problema das cheias, e diminuindo assim, os prejuízos causados pelas cheias, não só financeiros, como sociais.

Este artigo está organizado como segue. A Seção 2 apresenta os trabalhos da literatura relacionados com a pesquisa. A Seção 3 apresenta a versão inicial do SIGMAOn. A seção 4 apresenta a extensão da ferramenta SIGMAOn para permitir a 
visualização de áreas alagadas sob a perspectiva de uma pessoa no solo. A seção 5 apresenta as considerações finais.

\section{Trabalhos Relacionados}

O trabalho desenvolvido por Souza et al. (2011) consiste no desenvolvimento de um SIG para mapeamento de áreas de risco e inundáveis no município de Carlos Chagas - SC. A ferramenta foi desenvolvida para a plataforma web, com acesso público e permite gerenciar, analisar e consultar regiões identificadas como áreas de risco ou sujeitas a alagamentos.

O trabalho de Chan e Mori (2011) apresenta o desenvolvimento de um sistema de informação geográfica para monitoramento de alagamentos no Japão, que utiliza Google Earth. A ferramenta oferece recursos de visualização 3D e utiliza as informações já disponibilizadas pelo governo japonês de monitoramento de alagamentos. Mesmo oferecendo recursos em 3D, não é possível obter visualização sob a perspectiva do solo, apenas aérea, com os recursos oferecidos pelo serviço do Google.

Enchentes.org é uma aplicação web desenvolvida por Kraemer (2014) e oferece visualização da situação da cidade, baseado no nível atual do rio. Além disso, oferece recurso de simulação de alagamentos, com nível de rio informado pelo usuário, bem como consulta de rotas em cenários de alagamento. A aplicação atualmente oferece os recursos para a cidade de Blumenau/SC. A visualização dos impactos acontece através de desenho dos pontos alagados sobre mapas do Google. A ferramenta também possibilita visualizar abrigos, supermercados, hospitais e outros locais no mapa.

Todas as ferramentas apresentadas evidenciam os esforços empregados para oferecer recursos de identificação e prevenção no que diz respeito a alagamentos. Mesmo oferecendo recursos de visualização dos impactos, nenhum dos trabalhos apresenta uma forma de exibição do cenário real de alagamento que uma pessoa teria. Um recurso de visualização de alagamentos sob a perspectiva do solo possibilitaria a qualquer pessoa ter uma noção mais realista do impacto em caso de desastre.

\section{SIGMAON}

SIGMAOn (Sistema para Monitoramento de Alagamentos On-line) é um sistema web desenvolvido na linguagem Java com o objetivo de permitir a simulação de alagamentos on-line. A aplicação foi desenvolvida para utilização por parte de órgãos governamentais, que passam a ter uma ferramenta para mensurar as regiões com potenciais alagamentos, mas também por parte dos cidadãos, que podem ter conhecimento das áreas de risco das cidades. O sistema utiliza serviços de mapas do Google para apresentar visualmente as informações aos usuários e permite simulação de pontos alagados e áreas alagadas e consulta de rotas não alagadas entre localidades de uma cidade.

O SIGMAOn possui acesso livre para qualquer cidadão, utiliza uma API do Google para a visualização de mapas e armazena informações sobre as coordenadas dos pontos alagáveis e de medição, com a finalidade de mapear uma cidade com suas respectivas cotas de cheias, e assim poder calcular quais áreas de uma cidade estarão alagadas em determinado cenário. 
O sistema desenvolvido conta com três cadastros: pontos de medição, de alagamento e de usuários. O cadastro de usuários pode ser acessado somente por usuários do tipo Administrador enquanto os outros dois cadastros são de responsabilidade das prefeituras. Cada cidade deve possuir ao menos um ponto de medição, que no sistema representa a localização do medidor, utilizado como fonte das cotas dos pontos de alagamento da cidade.

Após o cadastro dos pontos de medição, a prefeitura pode cadastrar os pontos de alagamento, que são informações coletadas pela defesa civil e prefeitura do município, e indicam os locais alagáveis e suas cotas de nível do rio em que tais pontos alagaram. Esta cota leva em consideração justamente o ponto de medição que está associado a ela. Ao cadastrar um ponto de alagamento, o sistema, com o auxílio de serviços do Google, coleta a elevação de coordenadas com cinquenta metros de distância entre si por uma área de um quilômetro quadrado ao redor do ponto de alagamento. Este mapeamento de elevações tem por objetivo representar a abrangência do ponto.

A tela inicial do sistema é a tela de simulação e pode ser observada na Figura 1. Para realizar uma simulação, o usuário deve primeiramente selecionar um estado e cidade. Em seguida o sistema centraliza o mapa presente na tela para exibir a cidade selecionada. Este mapa disponibiliza todos os comandos de navegação oferecidos pelo Google: movimentação lateral, para cima/baixo, rotação, zoom, visualização nos modos mapa e imagem de satélite bem como visualização com Google Street View.

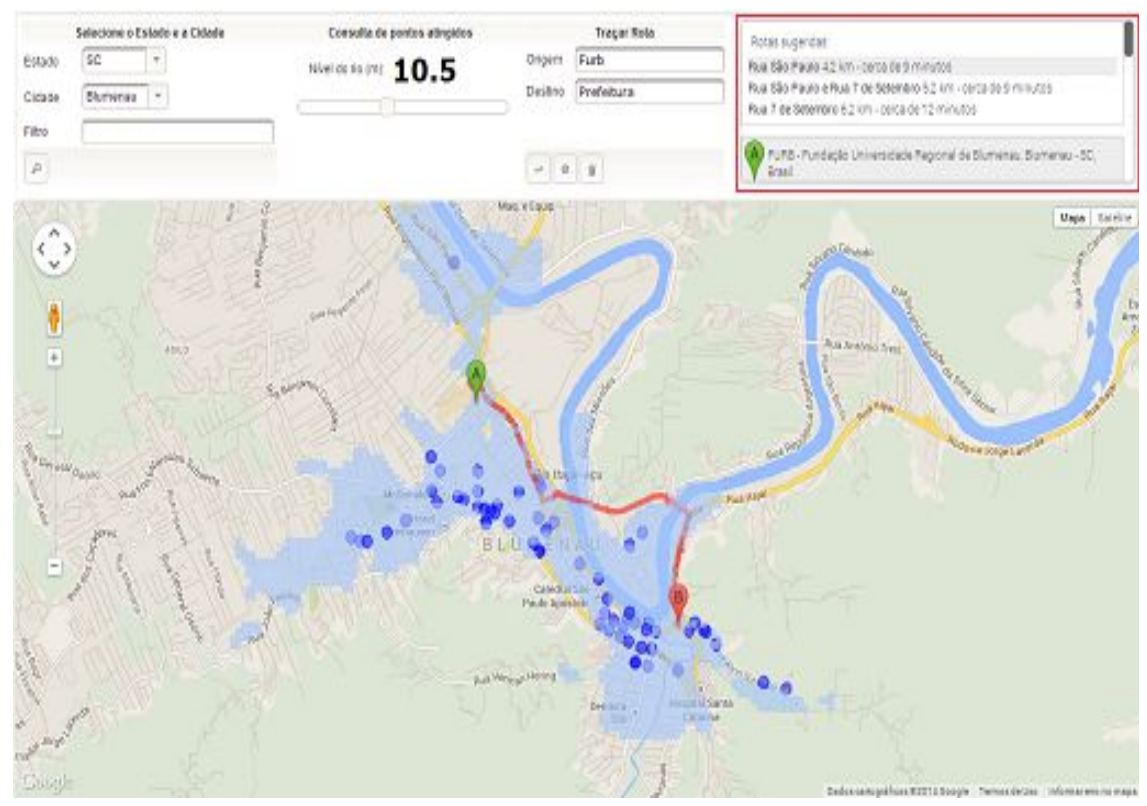

Figura 1 - Mapa de simulação de rota.

Na parte superior da tela, estão os componentes de entrada dos parâmetros para a simulação. À direita da escolha de estado e cidade, há um componente scroll, que permite ao usuário informar o nível do rio para a simulação. Ao mover o scroll, o sistema faz uma consulta dos pontos e regiões alagadas naquele local para o nível informado, destacando os mesmos no mapa, localizado logo abaixo na tela. Os pontos de alagamento são destacados sob a forma de círculos na cor azul. As regiões de alagamento são representadas por polígonos em azul claro. 
Além de visualizar o impacto e alcance de um alagamento, é possível também simular rotas para os alagamentos. Na parte superior direita da tela, é possível informar um destino e origem dentro de uma cidade para a rota. A Figura 1 apresenta a simulação de rota entre o trajeto A e B na cidade de Blumenau SC, considerando uma elevação do rio de 10,5 metros. Neste caso, a rota está desenhada em vermelho indicando que o percurso está bloqueado por causa da possível enchente. No painel superior direito destacado na Figura 1(a), é possível ainda verificar as rotas alternativas para o trajeto.

\section{Extensão da ferramenta SIGMAON}

A ferramenta foi desenvolvida na linguagem de programação Java na versão 1.7 do JDK. O ambiente de desenvolvimento escolhido foi o NetBeans 8.0. O sistema operacional utilizado durante o desenvolvimento foi o Windows 8 . O servidor de aplicação escolhido para execução foi o Apache Tomcat 7.0.

Para a implementação da ferramenta foi utilizado o framework JSF 2.0, juntamente com a biblioteca de componentes Primefaces, na versão 3.5. Primefaces é uma biblioteca de componentes JSF e com suporte a AJAX. Para a troca de mensagens entre as classes Java e os arquivos JavaScript foi utilizada a tecnologia JSON.

A manipulação dos mapas foi feitas com a Google Maps JavaScript API, na versão 3.0, que tornou possível a inserção do mapa no sistema, desenho de formas e adição de marcadores sobre o mapa, bem como quaisquer outros recursos de mapas do Google. A manipulação de imagens foi realizada com recursos do elemento do HTML 5 canvas, que possibilitou desenho de polígonos sobre fotos com o auxílio de JavaScript.

\subsection{Implementação da Extensão da Simulação de Alagamentos}

A funcionalidade de simulação de alagamentos foi estendida, mantendo todos os aspectos da versão anterior do sistema. Quando o usuário informa um nível de rio, o sistema já faz as atualizações tanto no mapa quanto na imagem, caso tenha alguma selecionada para simulação.

Com relação ao cálculo de nível do alagamento em função do nível de transbordo do rio, cada metro excedente no nível do rio gera um metro a mais no alagamento. Um exemplo do conceito pode ser observado na Figura 2, com um ponto de alagamento com cota de sete metros. No exemplo, há uma sequência que demonstra a situação do local com o rio em 2 metros (a), 3 metros (b), 7 metros (c) e 8 metros (d). Como pode ser observado, um local com cota de sete metros terá alagamento de um metro quando o rio estiver com oito metros em seu nível.

Inicialmente a ideia era utilizar recursos do Google Street View para visualização da simulação, entretanto a ausência de uma API para utilização de recursos dinâmicos do mesmo e a dificuldade em manipular os scripts gerados pelo Google fez com que a sua utilização fosse abandonada. Segundo Google (2014) a API permite apenas a inclusão estática de imagens geradas a partir do Google Street View para uma página da web. A única interação possível seria a inserção de marcadores customizados em mapas, que seriam mantidos ao entrar no modo Street View. 
Em seguida, houve uma tentativa de fazer reconhecimento automático das ruas em uma foto, também sem sucesso, em função da falta de precisão das técnicas e ferramentas existentes. Por fim, foi feito um estudo da possibilidade de realizar projeções sobre todo o solo alagado, considerando os obstáculos do cenário.

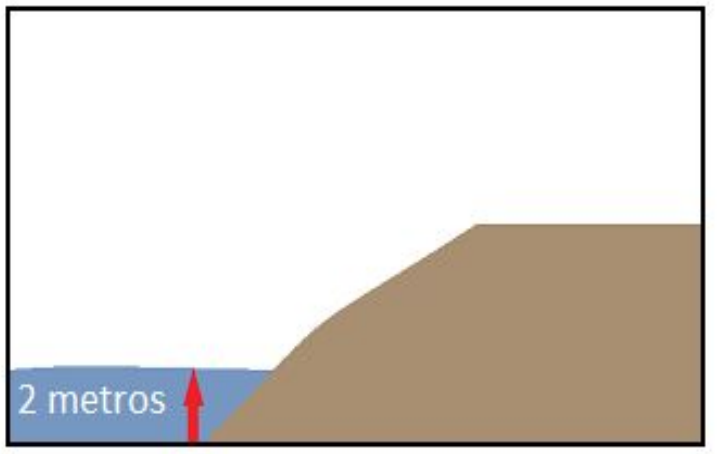

(a)

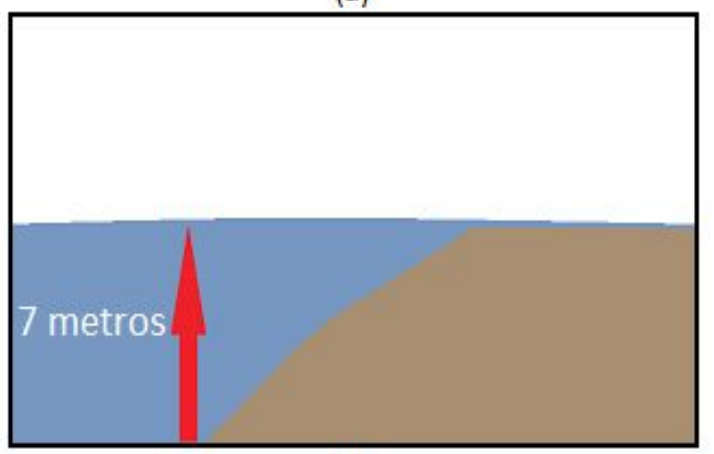

(c)

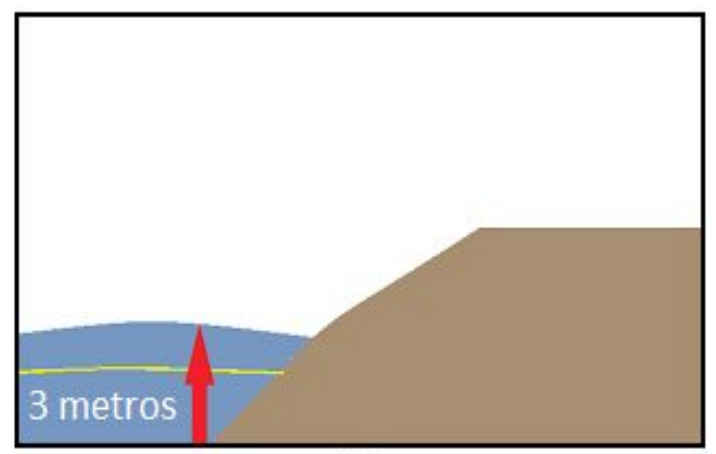

(b)

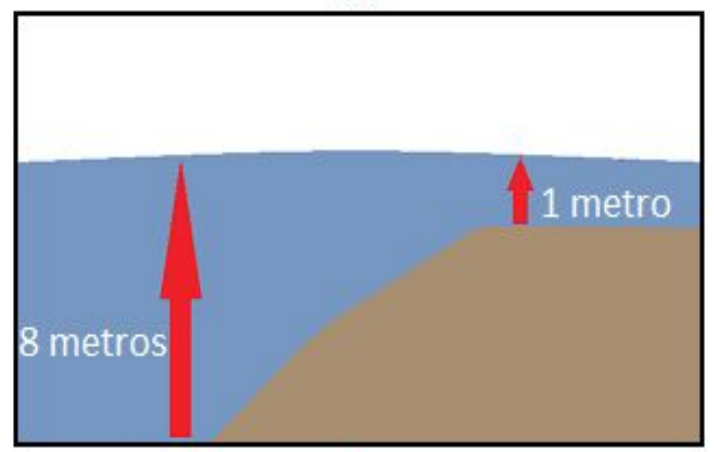

(d)

Figura 2 - Demonstração de evolução de alagamento: (a) 2 metros; (b) 3 metros; (c) 7 metros; (d) 8 metros.

Para mapear os pontos que interferem no desenho do alagamento, utilizou-se como base o trabalho realizado por Cristofolini (2004), que desenvolveu uma ferramenta para cálculo de impedimento de jogadores de futebol. A ferramenta utiliza o conceito de projeções em perspectiva para, a partir de uma foto estática, projetar o cenário em três dimensões. O usuário informa a localização dos limites das riscas do campo e a localização dos atletas envolvidos no lance, e o sistema cria uma animação tridimensional, evidenciando a legalidade ou não da posição do atleta.

O problema encontrado foi de que o sistema precisaria da localização de todos os obstáculos do cenário, bem como suas distâncias para a câmera. Entretanto, o número e natureza desses obstáculos variam muito de acordo com o local onde fio tirada a foto (muros, prédios, etc.), tornando a implementação demasiadamente complexa.

Como o insucesso na utilização de técnicas de reconhecimento automático de ruas, passou a ser necessário o mapeamento dos pontos que compõem uma rua na foto. Por fim, não foi possível finalizar a implementação do cadastro de fotos dos locais alagáveis, por falta de tempo hábil, sendo que a simulação é possível apenas com fotos de locais cadastrados diretamente no banco de dados. 
Com relação ao desenho sobre a imagem, dados os problemas encontrados para realizar a projeção sobre todo o solo, foi adotada a projeção do alagamento sobre toda a rua, como se a mesma fosse uma espécie de caixa fechada. Portanto, apenas as coordenadas da rua são levadas em consideração, ignorando o restante do terreno.

$\mathrm{Na}$ ferramenta proposta, cada imagem deverá ter largura de 640 pixels, visando uma padronização e melhor visualização na funcionalidade já existente de simulação, e estará associada a um ponto de alagamento. Além disso, deverão ser informados quatro pontos de referência para determinar as bordas da rua, bem como dois pontos de referência para informar onde estão as estacas em primeiro plano.

Para calcular as coordenadas do polígono que representa o alagamento, a foto deverá possuir duas estacas com um metro de altura uma de cada lado da rua, para que seja calculada a escala da imagem. Na sequência, o sistema calcula as coordenadas em pixels dos pontos que definem as retas que compõem o polígono que representa o alagamento. Além das estacas em primeiro plano utilizadas para definir a metragem em pixels de cada lado da rua, existem outras duas estacas mais ao fundo, uma de cada lado da rua, e que são utilizadas para informar por onde passa a rua na foto.

A distância entre as estacas em primeiro e segundo planos, de cada um dos lados da rua deve ser de, no máximo, dez metros, distância estipulada por questão de padronização, para que as estacas não estejam muito distantes. As retas formadas pelos lados da rua formam um ponto de fuga ao fundo, que é a intersecção destas retas. Além disso, a câmera deve estar posicionada no centro da rua escolhida a uma altura do solo entre um e dois metros, para que a visualização seja semelhante a que uma pessoa teria no local. A Figura 3 demonstra os conceitos visualmente em um exemplo.

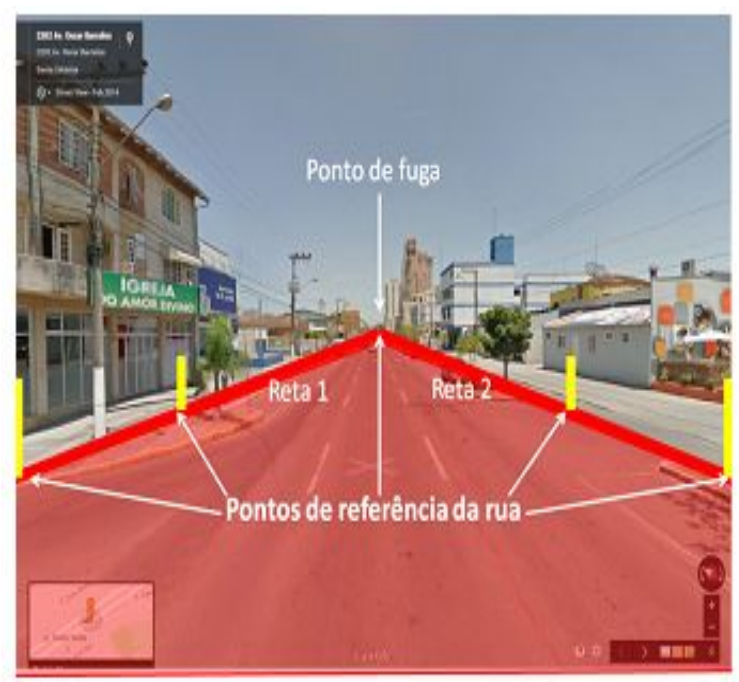

(a)

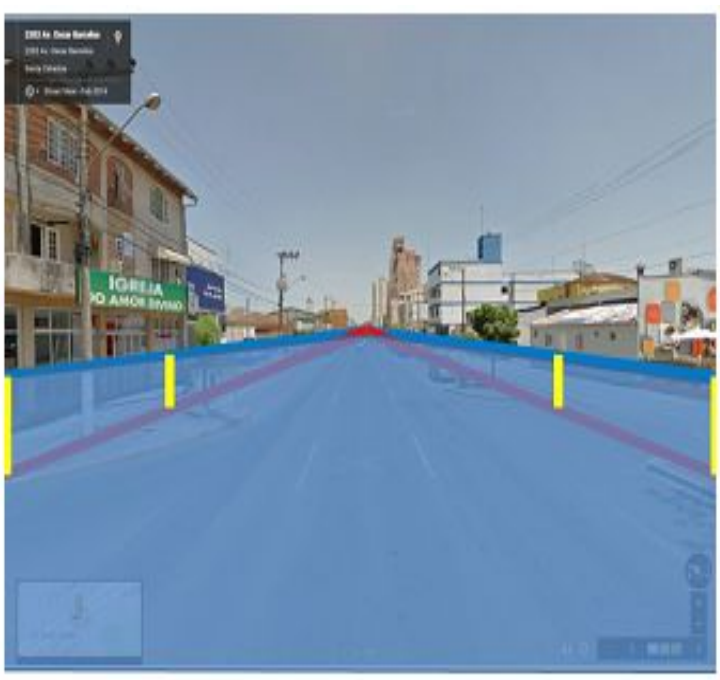

(b)

Figura 3 - Demonstração da projeção de uma rua sobre uma foto.

O exemplo demonstrado na Figura 3 ilustra como a ferramenta interpreta a parte da imagem que será considerada rua em (a). Essa interpretação é feita com base nas coordenadas da rua, armazenadas em banco de dados. Em (b) é possível identificar as estacas de cada um dos lados da rua em amarelo e um desenho de alagamento na altura 
das estacas em primeiro plano. Ao fundo de cada uma das imagens, o ponto de intersecção das retas é o ponto de fuga de cada uma delas.

A imagem, mesmo que estática e em 2D representa um ambiente tridimensional e que, portanto, deve ser projetado em perspectiva. Para tal, é calculado um ponto de intersecção entre as duas retas, que é o ponto de fuga, representando o limite de alcance da rua no campo de visão. Na Figura 4 é possível observar um exemplo de foto com as estacas dos dois lados da rua.

Os dados obtidos a partir dos valores das estacas são importantes para o desenho do polígono de alagamento, pois servem de parâmetro para calcular as retas de cada um dos lados da rua, bem como o ponto de intersecção formado por elas.

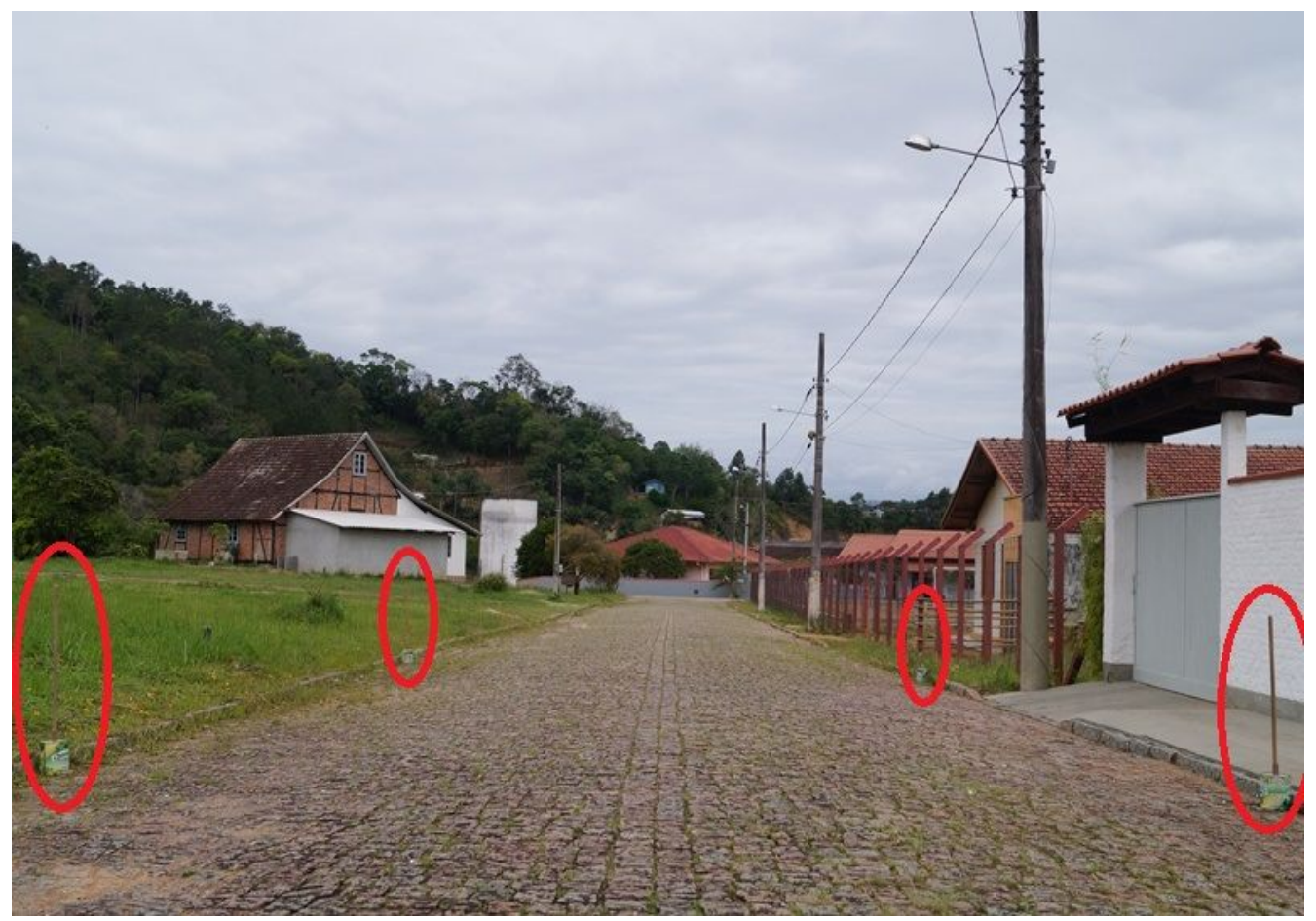

Figura 4 - Exemplo de foto de local alagável com estacas.

\subsection{Execução da funcionalidade de projeção}

Na Figura 5, é possível observar um exemplo de uma sequência de simulações. Em (a), o nível informado é de 14.8 metros, abaixo da cota do local e, portanto não alagado. Em (b), (c) e (d) é possível observar a sequência de níveis informados 15.8, 16.2, e 16.5 respectivamente, ocasionando diferentes níveis de alagamento no local.

É possível observar na Figura 5 que a abordagem de projetar o alagamento como se a rua fosse uma caixa fechada nem sempre pode ser a melhor escolha. No lado direito da rua, a abordagem funciona, uma vez que há um muro que faz com que a região alagável coincida com a rua. Já no lado esquerdo, como não há nenhum obstáculo, fica evidente que a região desenhada não é totalmente fiel ao cenário real. 


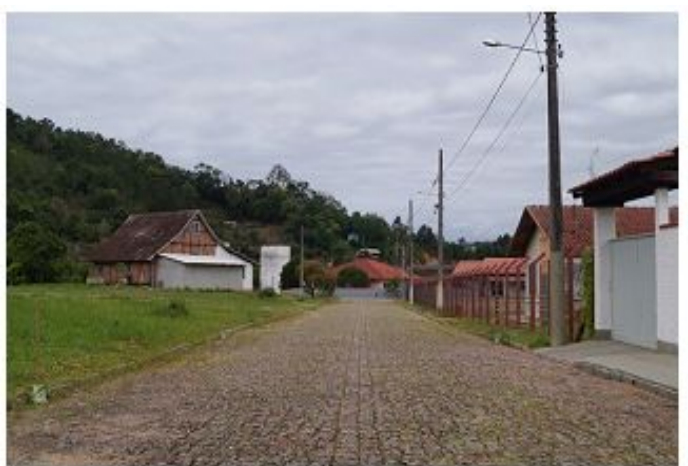

(a)

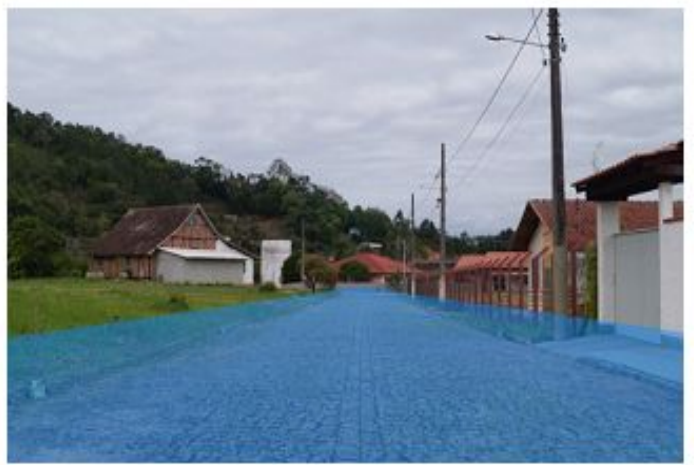

(c)

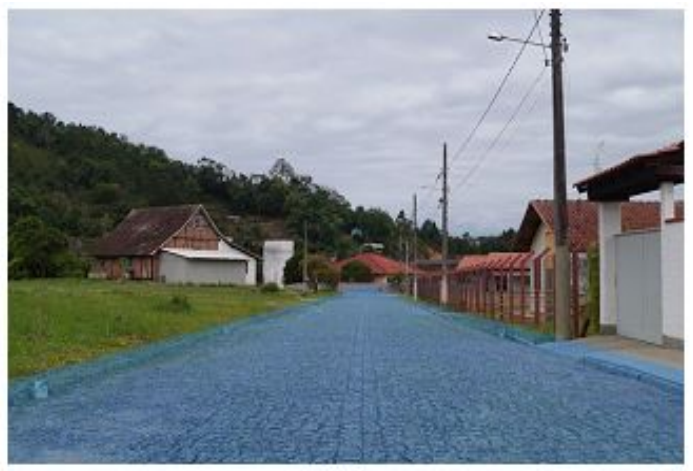

(b)

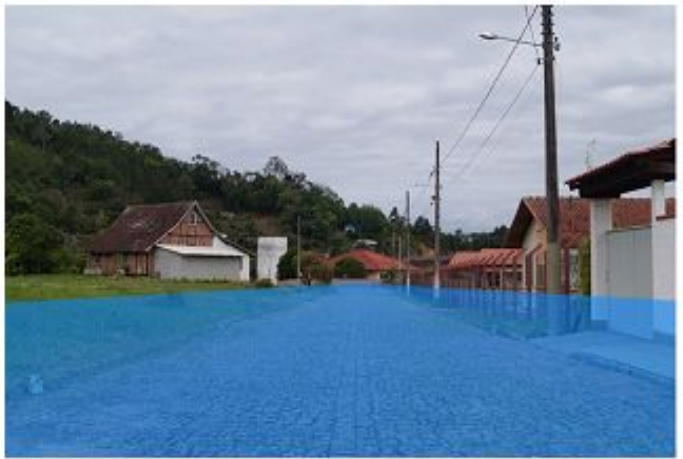

(d)

Figura 5 - Simulação com fotos com diferentes níveis de alagamento.

\section{Considerações finais}

A proposta deste trabalho consistiu na extensão do SIGMAOn. A extensão proposta consiste na simulação de alagamentos com fotos, sob a perspectiva do solo, para que se possa ter uma melhor noção do impacto nos locais alagáveis.

Para realizar a simulação, a ferramenta aplicou conceitos de geometria e projeções em perspectiva para desenhar a área alagada sobre uma foto. Para tal, foram utilizados alguns recursos de canvas HTML 5 para desenhar sobre imagens, além do framework JSF, da API de mapas do Google e JSON para troca de mensagens entre classes Java e variáveis JavaScript.

O trabalho oferece uma forma de visualização dos impactos de alagamentos sob a perspectiva do solo. É possível realizar simulação sobre fotos, utilizando conceitos de retas para projetar a região alagada, que compreende apenas a parte da rua na imagem. Esta abordagem funciona bem em cenários em que existem muros, casas, prédios ou outros obstáculos ao lado da rua. Entretanto, em locais com áreas abertas de solo a abordagem não é fiel à realidade, por dar a impressão de que o alagamento não atinge regiões que não compreendam a rua.

A partir desta ferramenta e tendo em vista cenários em que a abordagem não é totalmente realista, é possível evoluir o simulador com perspectiva do solo para que passe a considerar obstáculos no cenário, de forma a projetar o alagamento sobre todo o solo. Outro trabalho futuro envolve estender o sistema de modo que seja possível 
também fazer o monitoramento em tempo real dos rios, permitindo que seja possível a visualização de regiões alagadas em tempo real.

\section{Referências}

Câmara, G., Casanova, M.A., Hemerly, A.S., Magalhães, G.C., Medeiros, C.M.B. (1996) Anatomia de Sistemas de Informação Geográfica. São José dos Campos: INPE.

Chade, J. (2012) Mudança do clima custou quase o PIB brasileiro. Estadão, São Paulo. Disponível em: <http://www.estadao.com.br/noticias/impresso,mudanca-do-climacustou-quase-o-pib-brasileiro-,886037,0.htm>. Acesso em: 01 out. 2012.

Chan, Y., Mori, M. (2011) Web-based Flood Monitoring System Using Google Earth and 3D GIS. Geoscience and Remote Sensing Symposium (IGARSS), 2011 IEE International, Vancouver, v. 1, p. 1902-1905.

Cristofolini D. (2004) Protótipo de Um Ambiente Virtual Tridimensional para Utilização no Cálculo de Impedimento de Jogadores de Futebol. FURB. Trabalho de Conclusão de Curso, Ciências da Computação.

Floriano, D., Scoz, D., Melo, D.K.R., Sevegnani, J.A., Santos, F. (2014) SIGMAOn Sistema de Informação Geográfica para Monitoramento de Alagamentos On-line. In: $5^{\circ}$ Workshop de Computação Aplicada à Gestão do Meio Ambiente e Recursos Naturais (WCAMA), Brasília, p. 1215-1224.

Google. (2014) Google Street View Image API. Disponível em: <https://developers.google.com/maps/terms?hl=pt-br>. Acesso em: 11 nov. 2014.

Goodchild, M. (1993) A perspective on the Sate of Environmental Smulation. In: Goodchild, M.; Parks, B.; Steyaert, L. (Editores) Environmental Modelling with GIS. Oxford University Press.

Guidini M.P. (2007) Aplicação de Algoritmos de Agrupamento para Análise de Tráfegos Aéreos Desconhecidos em Sistemas de Informações Geográficas. São José dos Campos: ITA.

Kraemer, J. (2014) Enchentes.org. Disponível em: <http://enchentes.org/blumenau/>. Acesso em: 13 nov. 2014.

Presidente Getúlio. (2012) Presidente Getúlio decreta Situação de Calamidade Pública. 2011. Disponível em <http://www.presidentegetulio.sc.gov.br/conteudo/? item $=7879 \& \mathrm{fa}=1 \& \mathrm{~cd}=112693>$. Acesso em: 05 out. 2012.

Rio do Sul. (2012) Relato Enchente 1983. Disponível em: $<$ http://www.riodosul.sc.gov.br/portal/principal.php?pg=1787>. Acesso em: 05 out. 2012.

Souza, V.A., Rosa, M.B. de A., Santos, C.M., Ribeiro, C.A. de M., Leite, D.A. (2011) Sistemas de informação geográfica no mapeamento de áreas de risco no município de Carlos Chagas - MG. Revista de Ciência e Tecnologia do Vale do Mucuri, Teófilo Otoni, v. 1, n. 3 , p. 18-33.

Wiese, H. (2011) De Neu-Zürich a Presidente Getúlio. 3 ed. Ibirama: Edigrave. 462 p. 